Disclosure of Interest: None declared

DOI: 10.1136/annrheumdis-2017-eular.5970

\section{AB0685 SECUKINUMAB PROVIDES SUSTAINED IMPROVEMENTS IN WORK PRODUCTIVITY AND HEALTH RELATED QUALITY OF LIFE IN PATIENTS WITH ANKYLOSING SPONDYLITIS: LONG-TERM RESULTS FROM MEASURE 1 AND MEASURE 2}

A. Deodhar ${ }^{1}$, P.G. Conaghan ${ }^{2}$, V. Strand ${ }^{3}$, A. Boonen ${ }^{4}$, G. Ferraccioli ${ }^{5}$, F. Van den Bosch ${ }^{6}$, V. Bhosekar ${ }^{7}$, B. Porter ${ }^{7}$, K. Gandhi ${ }^{7}$, S. Jugl ${ }^{8} .{ }^{1}$ Oregon Health \& Science University, Portland, Oregon, United States; ${ }^{2}$ University of Leeds, Leeds, United Kingdom; ${ }^{3}$ Stanford University School of Medicine, Palo Alto, CA, United States; ${ }^{4}$ Maastricht University Medical Centre, Maastricht, Netherlands;

${ }^{5}$ Catholic University of the Sacred Heart, Rome, Italy; ${ }^{6}$ Ghent University Hospital, Ghent, Belgium; ${ }^{7}$ Novartis Pharmaceuticals Corporation, East Hanover, United States; ${ }^{8}$ Novartis Pharma AG, Basel, Switzerland

Background: Patients (pts) with ankylosing spondylitis (AS) experience significant restrictions in work productivity and health-related quality of life (HRQoL). Secukinumab (SEC) demonstrated rapid improvements in signs, symptoms and physical functioning in pts with AS. ${ }^{1}$

Objectives: To assess whether the beneficial effects of SEC on AS signs and symptoms were reflected in improvements in work productivity and HRQoL in the overall population and in TNF inhibitor (TNF)-naïve pts and pts with an inadequate response or intolerance to TNF inhibitors (TNF-IR) for up to 52 weeks (wks) in MEASURE 2 and 104 wks in MEASURE 1.

Methods: 371 and 219 pts were randomized to SEC or placebo (PBO) in MEASURE 1 ( $10 \mathrm{mg} / \mathrm{kg}$ IV followed by 150 or $75 \mathrm{mg} \mathrm{SC}$ ) and MEASURE 2 (150 or $75 \mathrm{mg} \mathrm{SC}$ ), respectively. At Wk 16 , PBO pts were re-randomized to SEC 150 or $75 \mathrm{mg}$ SC (PBO pts with ASAS20 response at Wk 16 were switched to SEC at Wk 24 in MEASURE 1). Productivity was measured using the Work Productivity and Activity Impairment-General Health (WPAI-GH) questionnaire, which includes questions to assess absenteeism, presenteeism and overall work productivity impairment in employed pts, and general activity impairment in all pts during the preceding 7 days $(0-100 \%)$. HRQoL was assessed with the ASQoL questionnaire (0-18 points). Across both studies, approximately $69 \%$ of pts were TNF-naïve and $31 \%$ were TNF-IR. Observed data are presented from the full analysis set and in subgroups stratified by prior TNF exposure. Only data with the approved dose (SEC $150 \mathrm{mg}$ ) are shown.

Table. WPAL-GH and ASQOL outcomes in MEASURE 1 and MEASURE 2 through Week 104

\begin{tabular}{|c|c|c|c|c|c|c|}
\hline & \multicolumn{3}{|c|}{ MEASURE 1} & \multicolumn{3}{|c|}{ MEASURE $2^{\circ}$} \\
\hline & Overall & TNF-native & TNF-IR & Orecall & TNF-naive & TNFGR \\
\hline \multicolumn{7}{|c|}{ WPAN $\mathrm{CH}^{5}$ (change from BL) } \\
\hline \multicolumn{7}{|c|}{ 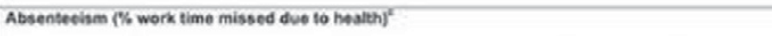 } \\
\hline \multirow{2}{*}{ wh s2 } & -2.1 & -3.5 & 30 & -49 & -128 & 7.1 \\
\hline & $(n=60)$ & $(n+47)$ & $(n=13)$ & $(n=38)$ & $(n=23)$ & (n=15) \\
\hline Wk 104 & 1.3 & 02 & $\begin{array}{c}6.8 \\
(n=8)\end{array}$ & - & - & - \\
\hline \multicolumn{7}{|c|}{ Presenteeism (\% impairment whilo working due to besith) } \\
\hline \multirow{2}{*}{ wh 52} & -20.2 & -21.6 & -149 & -19.2 & -25.5 & -10.0 \\
\hline & $(n=57)$ & $(n-45)$ & $(n=12)$ & $(n=37)$ & $(n=22)$ & $(n=15)$ \\
\hline \multirow{2}{*}{ Wk 104} & -25.1 & -278 & -11.3 & - & - & - \\
\hline & & $(n+41)$ & & & & \\
\hline \multicolumn{7}{|c|}{ Work Productivity (S overall work impairment due to health) } \\
\hline \multirow{2}{*}{ wosz } & -21.2 & -202 & -13.8 & -21.3 & -20.5 & -7.9 \\
\hline & $(n=87)$ & $(n=45)$ & $(n=12)$ & $(n=37)$ & $(n+23)$ & $(n \times 14)$ \\
\hline \multirow[t]{2}{*}{ Wh 104} & -23.0 & -26.1 & -69 & - & - & - \\
\hline & & & & & & \\
\hline \multicolumn{7}{|c|}{ Activify timpairment (S activity impairment due to heaith)" } \\
\hline \multirow{2}{*}{ Wh 52} & $-25,4$ & -27 & -20.8 & -28.4 & -30.5 & -18.6 \\
\hline & $(n+107)$ & $(n+\infty)$ & $(n \times 24)$ & (nะ61) & $(n=40)$ & $(n \times 21)$ \\
\hline \multirow{2}{*}{ Wh. 104} & -27.3 & -27.5 & -26.7 & & & \\
\hline & (n०85) & (ค॰6n) & $(n-18)$ & - & - & - \\
\hline \multicolumn{7}{|c|}{ Asool (change from Bt) ${ }^{20}$} \\
\hline \multirow{2}{*}{ Wx 52} & -47 & -50 & -34 & -52 & -6.0 & -3.7 \\
\hline & (nateg) & (n=ts) & $(n=24)$ & (n=61) & $(n=40)$ & $(n=21)$ \\
\hline \multirow{2}{*}{ Wx 104} & -4.8 & -5.0 & -4.1 & & & \\
\hline & (n=86) & $(\rho+68)$ & $(n=18)$ & - & - & - \\
\hline
\end{tabular}

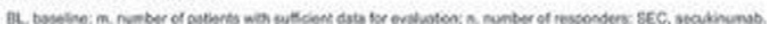

Results: At baseline (BL), 77 of 125 and 45 of 72 randomized pts were employed and working in the SEC groups in MEASURE 1 and 2, respectively. Improvements in all WPAI domains were observed with SEC in the overall, TNF-naïve and TNF-IR populations at Wk 16 in both studies, and effects were generally sustained through Wks 52 and 104 (Table). In MEASURE 1, activity impairment in the total group improved by $49 \%$ and overall work productivity in those employed improved by $45 \%$ from BL at Wk 104. Improvements were $51 \% / 49 \%$ in TNF-naïve and $42 \% / 19 \%$ in TNF-IR pts, respectively. In MEASURE 2, activity impairment and work productivity improved by $43 \%$ and $40 \%$ vs BL, respectively at Wk 52 ; improvements in activity impairment/work productivity in TNF-naïve and TNF-IR pts were $49 \% / 54 \%$ and $32 \% / 16 \%$, respectively. Similar responses were seen in the other WPAI scores across both studies. Early improvements in ASQoL were sustained through Wk 104 in MEASURE 1 and Wk 52 in MEASURE 2. At Wk 104 of MEASURE 1, ASQoL scores had improved by $48 \%$ vs. BL with SEC; improvements were $50 \%$ and $39 \%$ in TNF-naïve and TNF-IR pts, respectively.

Conclusions: SEC provides sustained improvements in work productivity and ASQoL for up to 104 wks among AS pts, regardless of prior TNF exposure.

[1] Baeten. NEJM 2015;373:2534-48.

Disclosure of Interest: A. Deodhar Grant/research support from: Amgen, Abbvie, GSK, Eli Lilly, Janssen, Novartis, Pfizer, UCB, Speakers bureau: Eli Lilly, Janssen, Novartis, Pfizer, UCB, P. Conaghan Consultant for: Abbvie, BMS, Lilly, Novartis, Pfizer, Roche, Speakers bureau: Abbvie, BMS, Lilly, Novartis, Pfizer, Roche, V. Strand Consultant for: AbbVie, Amgen, BMS, Celgene, Celltrion, CORRONA, Genentech/Roche, GSK, Janssen, Lilly, Merck, Novartis, Pfizer, Regeneron, Samsung, Sanofi, and UCB, A. Boonen Grant/research support from: Merck, Pfizer, Abbvie and Amgen, Speakers bureau: Sandoz, Janssen, Lilly, G. Ferraccioli Grant/research support from: BMS, Roche, MSD, Speakers bureau: AbbVie, Pfizer, UCB.Roche, MSD, Eli Lilly, GSK, Novartis, F. Van den Bosch Consultant for: Abbvie, Bristol-Myers Squibb, Celgene, Eli Lilly, Janssen, Merck, Novartis, Pfizer, UCB, Speakers bureau: Abbvie, Bristol-Myers Squibb, Celgene, Eli Lilly, Janssen, Merck, Novartis, Pfizer, UCB, V. Bhosekar Employee of: Novartis, B. Porter Shareholder of: Novartis, Employee of: Novartis, K. Gandhi Shareholder of: Novartis, Employee of: Novartis, S. Jugl Shareholder of: Novartis, Employee of: Novartis

DOI: 10.1136/annrheumdis-2017-eular.1856

\section{AB0686 ASSOCIATION BETWEEN DRUG SERUM LEVELS AND DISEASE ACTIVITY IN ESPONDILOARTHRITIS PATIENTS TREATED WITH GOLIMUMAB}

C. Redondo ${ }^{1}$, A. Martínez ${ }^{2}$, C. Plasencia ${ }^{1}$, A. Jochems ${ }^{2}$, D. Pascual-Salcedo ${ }^{2}$, V. Navarro-Compán ${ }^{1}$, M.G. Bonilla ${ }^{1}$, I. Monjo ${ }^{1}$, A. Balsa ${ }^{1} .{ }^{1}$ Rheumatology;

2/mmunology Unit, la Paz University Hospital, Madrid, Spain

Background: Efficacy and safety of Golimumab (Glm) has been demonstrated for spondiloarthritis $(\mathrm{SpA})$. Nonetheless, there is little data determining an association between an optimal drug levels concentration and the maintenance of a good control of disease activity. In Spa-Paz cohort we defined previously an optimal Glm levels concentration associated with a good clinical response.

Objectives: To investigate the association between serum levels of Glm, based on the optimal concentration defined previously in Spa-Paz cohort, and disease activity in a larger cohort of $\mathrm{SpA}$.

Methods: Observational prospective SpA-Paz cohort study treated with GIm. Disease activity was measured by ASDAS and clinical improvement using Delta-ASDAS at baseline, 6 and 12 months of biologic therapy. ASDAS $<2.1$ was considered as low activity and clinically important improvement as DeltaASDAS >1.1. Drug levels were measured by ELISA at 6 and 12 months of therapy and classified in 3 groups based on the optimal concentration range previously defined in our cohort: Group $1:<0.7 \mathrm{mg} / \mathrm{L}$, group 2: $0.7-1.4 \mathrm{mg} / \mathrm{L}$, group 3 : $>1.4 \mathrm{mg} / \mathrm{L}$. At 12 months we made a LOCF analysis to include patient data (11 patients) with less than 12 months of treatment. We used the software Graph-Pad Prism 6 for statistical analysis.

Results: 46 patients of 79 with SpA treated with Glm were included in this study. The average age was 49 years old (age range 22-72 years old), 31 men $(67 \%)$ and 15 women $(33 \%) .22$ patients $(48 \%)$ were non-smokers and $13(28 \%)$ active smokers. $25(54 \%)$ were HLA-B27 positive. In total, 17 patients $(37 \%)$ were classified in group 1, $16(35 \%)$ in group 2 and $13(28 \%)$ in group 3 . At 12 months of therapy, most patients in low disease activity were in groups 2 and 3 but nevertheless, the majority of high disease activity patients were in group $3(76 \%$ in groups 2 and 3 vs. $41 \%$ in group 1 with ASDAS $<2.1 ; 24 \%$ in group 2 and 3 vs. $53 \%$ in group 1 with $A S D A S \geq 2.1 ; p<0.0001)$. Likewise, clinical improvement was significantly higher in groups 2 and 3 patients (62\% in groups 2 and 3 vs. $35 \%$ in group $1, p>0.0002$ ). There were no differences in clinical improvement between group 2 and 3.11 patients $(24 \%)$ discontinued the treatment, 1 for adverse effect and 10 for inefficacy, $50 \%$ of which (5 patients) were in group 1 at the suspension moment.

Conclusions: In our Glm treated SpA cohort, the majority of low activity patients and higher clinical improvement were classified in optimal or supraoptimal concentration group. Overoptimal concentration drug levels do not seem to contribute to major benefit in clinical improvement.

Disclosure of Interest: None declared

DOI: 10.1136/annrheumdis-2017-eular.5881 